\title{
LA EVOLUCIÓn DE LA POLÍTICA DE COOPERACIÓn INTERNACIONAL AL DESARROLLO DE ESPAก̃A
}

\section{The Evolution of the Spanish Policy of International Co-operation for Development}

\author{
José Miguel Calvillo Cisneros \\ Universidad Complutense de Madrid \\ E-mail: jcalvill@ucm.es
}

0 Autor

El objetivo de esta comunicación es evaluar la evolución de la política de cooperación al desarrollo internacional española desde su inicio hasta 2010. Esta política identifica el problema global de la pobreza, a cuya solución España contribuye dentro de un espacio coordinado con el resto de actores nacionales e internacionales, pero al mismo tiempo cubre también un espacio como herramienta de la política exterior del Estado.

La progresiva formulación y puesta en práctica de esta política pública hubo de tener en cuenta hitos relevantes, como son la transición política a la democracia, la aprobación de la Constitución de 1978, la incorporación a las Comunidades Europeas, el ingreso en los distintos bancos regionales de desarrollo, complementados por nuestra participación en todos aquellos organismos de carácter económico y financiero dedicados a la cooperación para el desarrollo, en particular los fondos y programas de la Unión Europea, así como un protagonismo activo en los programas de desarrollo y acción humanitaria del sistema de las Naciones Unidas.

Política exterior española; cooperación para el desarrollo; ayuda humanitaria. Spanish foreign policy; co-operation for development; humanitarian aid.

Key words 
The purpose of this article is to analyze the evolution of the Spanish international cooperation and development policy until 2010. Such policy identifies poverty as the global problem which Spain tries to solve in an international context. However, it is also a resource for the Country's foreign policy.

This public policy is developed taking into account some basic facts, such as the Transition to Democracy period (1977-1982), the recent new Constitution (1978), the integration into the European Communities (1986), the incorporation into the Regional Development Banks, as well as a more active participation in the EU Fundings and in the Programmes of Development and Humanitarian Aid of the United Nations system.

\section{Un breve repaso histórico al sistema español de cooperación internacional}

España, a finales de los años setenta, era considerada todavía por el Banco Mundial como un país en vías de desarrollo ${ }^{1}$ y, por este motivo, no disponía de una política de cooperación definida. En la década de los años 50 es un país receptor de ayuda al desarrollo y recibe, a partir de 1955, ayuda estadounidense. En 1959 pasa a formar parte del Banco Mundial y disfruta de su primer crédito en 1960. En esta etapa también formará parte de la Asociación Internacional de Desarrollo (AID), actualmente Asociación Internacional de fomento (AIF). Siempre como un país receptor de ayudas económicas.

España fue miembro fundador del Fondo Africano de Desarrollo (1974) y participa desde 1976 en el Banco Interamericano de Desarrollo (BID). De esta manera, poco a poco, España se fue incorporando a distintos organismos internacionales de ayuda al desarrollo en calidad de socio receptor o donante. En 1976 se sitúa el punto de partida del sistema institucional responsable de la política española de cooperación con la creación del Fondo Español de Ayuda al Desarrollo (FAD). Un año después, España firma el último convenio de préstamo con el Banco Mundial y deja de ser considerada receptora de ayuda en 1981; en 1983 solicita salir de la lista de países receptores de Ayuda Oficial al Desarrollo (AOD) elaborada por el Comité de Ayuda al Desarrollo (CAD) de la OCDE (Organización de Cooperación y Desarrollo Económico) (Calabuig y Llanos, 2010).

En 1985 se crea el máximo órgano político especializado en cooperación al desarrollo: la Secretaría de Estado para la Cooperación Internacional y para Iberoamérica (SECIPI) dependiente del Ministerio de Asuntos Exteriores. Esta Secretaría será la instancia política responsable de la dirección, programación, control y evaluación de la política española de cooperación al desarrollo. Un año después, en 1986, España se incorpora a las Comunidades Europeas canalizando parte de su ayuda oficial a través de su presupuesto. Dos años más tarde, en 1988, se crea la Agencia Española de Cooperación al Desarrollo (AECI), dependiente de la SECIPI. Esta institución será la encargada de la ejecución de la cooperación y de la definición y gestión de programas y proyectos de desarrollo.

l La aplicación del término país en vías de desarrollo o incluso país emergente para algunos de los países menos desarrollados podría considerarse inapropiada. Este término no refleja la carga de dependencia que la gran mayoría de estos países tienen de otros poderes políticos y económicos y que les supone, en muchos casos, un lastre para poder llevar a cabo su propio crecimiento y, por tanto, desarrollo. 
España entra a formar parte del Comité de Ayuda al Desarrollo de la OCDE (CAD) en 1991 y con ello al sistema internacional de cooperación al desarrollo, asumiendo las directrices y criterios de este organismo. La entrada de España al CAD da por finalizado el proceso de incorporación de España al sistema internacional de ayuda al desarrollo como donante. España tiene, por tanto, casi tres décadas de experiencia acumulada pese a que se incorpora mucho más tarde que otros países al sistema de ayuda. Y, además, cuenta con una potencialidad que le permite diferenciarse del resto de países del entorno europeo: contar con una experiencia como receptor, fundamental para diseñar una política responsable como donante.

En línea paralela a la gubernamental, los años ochenta se caracterizan por las crecientes demandas de participación de la sociedad civil canalizadas a través de las organizaciones no gubernamentales para el desarrollo (ONGD). Hasta 1994, con el movimiento social por el 0,7\%, no se comenzarán a registrar en el seno de la sociedad civil importantes movilizaciones en torno a la preocupación de la calidad y cuantía de la ayuda española (Calabuig y Llanos, 2010). Las consecuencias directas de dichas movilizaciones fueron, por un lado, la firma de un "pacto por la solidaridad" por el que los partidos parlamentarios se comprometieron a incrementar la AOD con el objetivo de aproximarse al 0,7\% del PIB; y por otro, la creación en 1995 del Consejo de Cooperación para el Desarrollo, instancia consultiva participada por los principales agentes involucrados en la cooperación (administración pública, ONGD, universidades, empresas, fuerzas sociales y expertos/as) con el objetivo de facilitar el diálogo entre la administración pública, las ONGD y otros agentes sociales.

En definitiva, España se ha ido incorporando al sistema de cooperación internacional paulatinamente, pasando por todas sus fases, lo que le ha permitido definir una política pública de cooperación que refleja las inquietudes solidarias de todos los actores de desarrollo españoles y, al mismo tiempo, incorporada a la acción exterior del Estado.

\section{El sistema de cooperación internacional para el desarrollo de España}

La política pública de la cooperación al desarrollo internacional identifica el problema global de la pobreza al que España pretende contribuir a su solución, dentro de un espacio coordinado con el resto de actores nacionales e internacionales. Sin embargo, y como veremos a lo largo de este documento, esta política pública viene a cubrir, además, un espacio como herramienta de la política exterior del Estado.

La Ley 23/1998, de 7 de julio, de Cooperación Internacional para el Desarrollo establece que la política española de cooperación para el desarrollo tiene básicamente su origen en la declaración contenida en el preámbulo de la Constitución de 1978, en la que "la Nación española proclama su voluntad de colaborar en el fortalecimiento de unas relaciones pacíficas y de eficaz cooperación entre todos los pueblos de la Tierra”. Desde esta generalidad jurídica conviene establecer cuáles han de ser las principales características de lo que es la cooperación española en todas sus vertientes (Calvillo y Yuste, 2015).

En primer lugar, la cooperación española se caracteriza por tener un importante peso político siendo una herramienta fundamental de la acción exterior española. Así, la mencionada Ley 23/1998 afirma que "La política de cooperación internacional para el desarrollo constituye un aspecto fundamental de la acción exterior de los Estados democráticos [...]”. Y, al mismo

\section{Los años ochenta} se caracterizan por las crecientes demandas de participación de la sociedad civil canalizadas a través de las organizaciones no gubernamentales para el desarrollo (OnGD) 
tiempo, la cooperación española adquiere un contenido solidario en relación con la asunción del compromiso de contribuir a reducir la pobreza de aquellos países más necesitados o, como dice la Ley "[... aquellos países que no han alcanzado el mismo nivel de desarrollo, basada en una concepción interdependiente y solidaria de la sociedad internacional y de las relaciones que en ella se desarrollan”. Esta doble dimensión, política y solidaria, va a caracterizar la cooperación internacional española.

La estructura institucional del sistema de cooperación español no depende en exclusiva de un solo ministerio, sino que ocupa parte de las agendas de varios, todos aquellos en los que sus líneas de acción influyen en la política exterior del Estado. Sin embargo, sí que existe un liderazgo en la definición de la política de cooperación que es el ejercido por el Ministerio de Asuntos Exteriores y de Cooperación (MAEC). Así, la política de cooperación internacional española depende del MAEC, más concretamente de la Secretaria de Estado de Cooperación Internacional y para Iberoamérica (SECIPI). De este órgano depende la formulación, dirección, ejecución, seguimiento y evaluación de la política exterior para Iberoamérica, la de cooperación internacional para el desarrollo y la coordinación de la acción cultural exterior. De la SECIPI dependen la Secretaría General de Cooperación Internacional para el Desarrollo y la Dirección General para Iberoamérica. Cuenta además con dos instituciones adscritas, la Agencia Española de Cooperación Internacional para el Desarrollo (AECID) y el Instituto Cervantes. La Academia de España en Roma depende funcional y orgánicamente de esta Secretaría de Estado.

La AECID es el órgano encargado de ejecutar y coordinar la política de cooperación del Estado. Los actores del sistema de cooperación español son diversos y plurales. Partiendo de un modelo simple de categorización, podemos establecer una división de actores entre públicos, privados y mixtos. Dentro del sector público o institucional el principal actor es el Gobierno de España, con varios ministerios implicados en el sistema de cooperación internacional, fundamentalmente el MAEC, el Ministerio de Economía y Competitividad, el Ministerio de Defensa, el Ministerio de Justicia a través de contribuciones a planes de formación en el sector justicia y, así, podríamos enumerar la práctica totalidad de los ministerios que, en menor medida, tienen un papel como actores del sistema gubernamental en relación con la cooperación.

Tabla 1. Principal distribución de la AOD española por actores (2014)

\begin{tabular}{|l|r|}
\hline Actor & \multicolumn{1}{|c|}{ Total en Euros } \\
\hline Ministerio de Hacienda & 772.503 .192 \\
\hline AECID & 251.702 .216 \\
\hline Ministerio de Economía & 220.182 .088 \\
\hline Comunidades autónomas & 108.890 .502 \\
\hline Entidades locales & 53.545 .270 \\
\hline SECIPI & 36.716 .199 \\
\hline Ministerio de Empleo & 15.867 .153 \\
\hline Universidades & 10.023 .941 \\
\hline Ministerio Defensa & 9.677 .531 \\
\hline Ministerio Educación, Cultura y Deporte & 883.643 \\
\hline
\end{tabular}

Fuente: Intermón Oxfam (2015) 
Como podemos observar en tabla 1, el ministerio con mayor implicación presupuestaria en la política de cooperación internacional es el de Hacienda y Administración pública (44\%), seguido del Ministerio de Asuntos Exteriores y de Cooperación (Suma de AECID y SECIPI) (31\%) y del de Economía y Competitividad (22\%). De estos datos se denota que la cooperación al desarrollo no es una cuestión exclusiva de la acción del Estado con la reducción de la pobreza sino que, además, tiene un peso importante en la política económica del Estado (más adelante el lector podrá tener más información al respecto en el apartado referido a los instrumentos de la cooperación internacional española).

Dentro de la categorización de los actores públicos se encuentran aquellos actores que forman parte de lo que se denomina la cooperación descentralizada, es decir, las comunidades autónomas (CCAA) -prácticamente todas las CCAA disponen de agencias o departamentos encargados de gestionar la cooperación al desarrollo de sus territorios-, las diputaciones provinciales y los ayuntamientos. En este apartado también debemos mencionar a las universidades públicas, aunque también merecen una mención importante en el apartado de actores privados. Y, por último, hacer una especial mención a las empresas públicas que intervienen en el sistema de cooperación.

En segundo lugar, en el sector privado existe una nutrida representación de actores de cooperación. Así, se encuentra el actor por excelencia del sistema de cooperación internacional que son las organizaciones no gubernamentales (ONG). Dentro de las ONG los ámbitos de especialización también son muy diversos. Destacamos las de carácter únicamente humanitario, las de desarrollo y, dentro de este ámbito se encuadran numerosas ONG, dependiendo del sector en el que trabajen, de denuncia y también aquellas que pueden pertenecer a varias de las especialidades descritas, es decir, ser de desarrollo, humanitarias y de denuncia. La gran mayoría de las ONG se coordinan a través de la Coordinadora de ONG para el Desarrollo (CONGNDE).

Siguiendo en el sector privado, cada vez van adquiriendo un mayor protagonismo en el sistema de cooperación internacional las empresas que, a través de la responsabilidad social corporativa (RSC) o de fundaciones adscritas a la propia empresa, desarrollan actividades relacionadas con la cooperación al desarrollo. Y, por supuesto, una atención especial a la cooperación internacional llevada a cabo por las universidades privadas.

Esta amalgama de actores deben respetar los objetivos y prioridades que marca la política de desarrollo, puesto que esta es el resultado de un ejercicio de coordinación entre los representantes de cada uno de estos actores y el Gobierno, así como del Gobierno con las direcciones responsables de la Comisión Europea encargadas de coordinar y definir las grandes líneas maestras a nivel comunitario.

En relación con los instrumentos de la cooperación española existen varias modalidades que dependen del tipo de cooperación que se vaya a llevar a cabo. En función de la naturaleza de la ayuda, la cooperación puede ser financiera o en especie. Un ejemplo de cooperación en especie es la cooperación técnica, modalidad dirigida a la formación profesional de recursos humanos del país socio. Según las condiciones de entrega de la ayuda, la cooperación puede ser reembolsable o no reembolsable. Además, hay que tener en cuenta la cooperación ejecutada por varios, donde nos encontramos con la cooperación delegada y la cooperación triangular, que son modalidades basadas en las vías de canalización de la ayuda: la cooperación delegada se produce cuando una o varias agencias de cooperación encomiendan a otra la realización de toda o parte de las actividades que involucra la ayuda, y en la cooperación triangular dos o más países asocian sus recursos en
La estructura institucional del sistema de cooperación español no depende en exclusiva de un solo ministerio, sino que ocupa parte de las agendas de varios 
beneficio de un tercero. Por último, el referente de la adaptación a las políticas de desarrollo de los países receptores es la modalidad de ayuda programática. Esta modalidad está basada en un apoyo coordinado a un plan o programa de desarrollo del país socio.

Por último, y no por ello menos importante, el Fondo para la Promoción del Desarrollo (FONPRODE), administrado por la AECID, se configura como uno de los principales instrumentos financieros de la cooperación española. El FONPRODE garantiza la capacidad de respuesta de la cooperación española a las necesidades y objetivos fijados por nuestra política de cooperación al desarrollo, convirtiéndolo en uno de los principales canales de ejecución de ayuda al desarrollo. El FONPRODE, en vigor desde 2011, puede financiar operaciones de naturaleza no reembolsable y reembolsable, tanto de deuda como de capital. Su cartera incluye un elevado número de operaciones de carácter no reembolsable y de carácter reembolsable.

La AOD reembolsable está formada por los flujos de financiación pública dirigidos a países en desarrollo que, a pesar de su carácter reembolsable, reúnen ciertas condiciones de concesionalidad acordadas en el CAD. Como su propio nombre indica, forma parte del cómputo de la AOD neta de un donante. La cooperación financiera reembolsable puede estar formada por otros flujos similares que, sin embargo, no computan de esta forma (Olivié, 2014).

En definitiva, la cooperación financiera reembolsable se realiza a través de tres tipos de instrumentos: deuda, inversión y garantías. Y es precisamente esta cooperación financiera reembolsable la que está asistiendo a profundos cambios en los últimos años, ya que está siendo objeto de mayor atención por parte de los países e instituciones donantes, hasta el punto de que podemos estar asistiendo a un profundo cambio de paradigma y de la visión del desarrollo, tal y como había sido comprendida hasta ahora en el ámbito de la ayuda internacional.

Los instrumentos de cooperación son las opciones y herramientas finales a través de las cuales la ayuda se materializa y ejecuta en un determinado contexto para apoyar la consecución de los objetivos planteados. Dos instrumentos significativos de la cooperación española son los convenios, programas y proyectos de cooperación.

\section{Gráfico 1. Evolución de la AOD española (RחB) en comparación con los países del CAD en \% (2000-2014)}

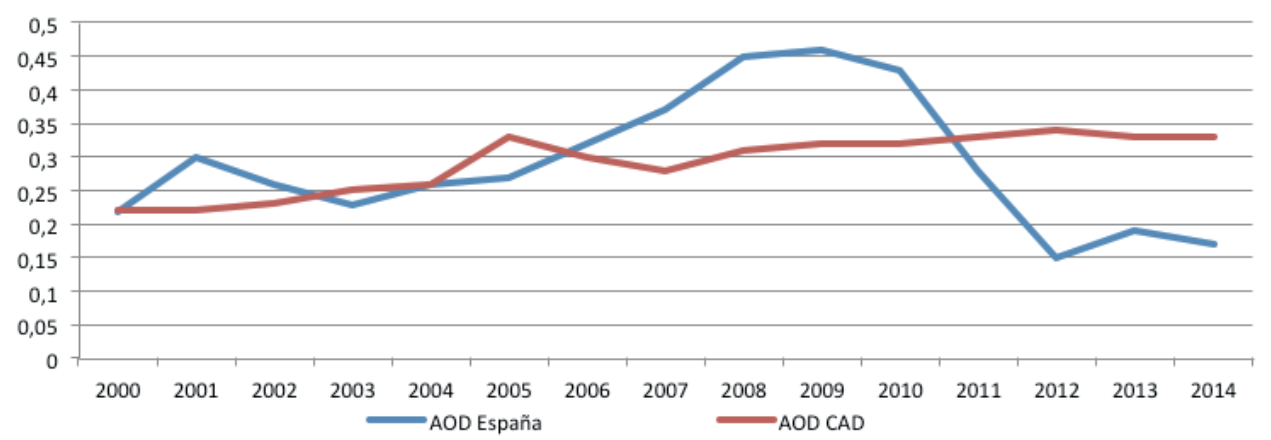

Fuente: Economistas Sin Fronteras a través de datos del Informe de Ayuda al Desarrollo de la Secretaría de Estado de Cooperación Internacional y para Iberoamérica. Gráfico elaboración propia

Como podemos observar en el gráfico 1, la evolución de la AOD española se ha caracterizado por su volatilidad y por estar muy ligada al color de los Gobiernos que han dirigido la política 
de desarrollo, más que a ofrecer una respuesta a una política de cooperación coherente y coordinada con el resto de la comunidad donante y, además, muy lejos de conseguir la meta propuesta del $0,7 \%$.

Esta fuerte carga ideológica, sobre todo en los últimos años, viene a deslucir el componente solidario de la política de cooperación. Como podemos observar en el gráfico 1, la evolución cuantitativa de la AOD española ha ido a contracorriente de la dinámica del CAD caracterizada por la continuidad a pesar de los diversos ciclos económicos. En este sentido, cabe establecer dos críticas a la política de cooperación española. Por un lado, la influencia del ciclo económico en relación con las aportaciones de AOD española, de tal manera que cuando en la economía nacional aparecen indicadores de crecimiento positivos, la apuesta es la de aumentar los fondos de AOD y cuando la economía entra en niveles negativos de crecimiento la AOD desciende de forma exagerada. Este hecho es totalmente contrario a las dinámicas y recomendaciones del CAD. Y, en segundo lugar, existe una carga ideológica en torno a la AOD española, donde tanto los periodos de incremento como los de reducción corresponden a Ejecutivos diferentes. No obstante, cabe destacar que hasta 2010 la política de cooperación internacional de España ha sido una política de Estado y basada en el consenso absoluto de todas las fuerzas políticas con representación parlamentaria.

En relación con los propósitos de la política de cooperación española, el objetivo general es el de contribuir a reducir la pobreza mundial y al cumplimiento de los objetivos fijados por la comunidad internacional en relación con el desarrollo humano. Descendiendo un peldaño, los objetivos específicos de la cooperación española se pueden resumir de la siguiente manera:

Los Objetivos del Milenio, ahora Objetivos de Desarrollo Sostenible y los principios de eficacia y calidad de la ayuda son los principales objetivos de la Cooperación Española. El Plan Director 2013-2016 establece las líneas generales y directrices básicas de la política española de cooperación internacional para el desarrollo. España concentrará sus esfuerzos en 23 países de tres áreas geográficas prioritarias:

» América Latina y Caribe: Bolivia, Colombia, Cuba, Ecuador, El Salvador, Guatemala, Haití, Honduras, Nicaragua, Paraguay, Perú y República Dominicana.

» Norte de África y Oriente Próximo: Mauritania, Marruecos, poblaciones saharauis y territorios palestinos.

» África occidental: Malí, Níger y Senegal.

» África Central y Este: Etiopía, Guinea Ecuatorial y Mozambique.

» Asia: Filipinas.

En ellos, se primará la consolidación de los procesos democráticos y el Estado de derecho; la reducción de las desigualdades y de la vulnerabilidad a la pobreza extrema y a las crisis; el fomento de sistemas de cohesión social, enfatizando los servicios sociales básicos; la promoción de los derechos de las mujeres y la igualdad de género; la mejora en la provisión de los bienes públicos globales y regionales; la respuesta a las crisis humanitarias con calidad y la construcción de una ciudadanía global comprometida con el desarrollo.

Desde la perspectiva de los criterios, la cooperación española se fija la rendición de cuentas que supone la obligación tanto de informar y justificar como de asegurar una ayuda de calidad,

\section{La evolución} cuantitativa de la AOD española ha ido a contracorriente de la dinámica del CAD caracterizada por la continuidad a pesar de los diversos ciclos económicos 
incluyendo la asunción de las responsabilidades correspondientes. La responsabilidad comprende tres dimensiones complementarias y relacionadas entre sí: una definición clara y apropiada de su misión y sus objetivos; una gestión ética, transparente y eficiente de los recursos a su disposición en el marco de la legalidad vigente; y la contribución a resultados de desarrollo como fruto de su actividad.

\section{La acción humanitaria española}

La acción humanitaria española tiene una corta historia de aprendizaje en la que pasa de ser una herramienta de asistencia de emergencia o, en contextos más o menos difíciles, a constituirse poco a poco en una auténtica y consolidada acción humanitaria regida por los principios de la buena donación humanitaria (Good Humanitarian Donorship). Distinguiríamos dentro de la historia institucional de la AECID tres periodos marcados.

El origen y posterior desarrollo de la acción humanitaria están estrechamente vinculados a la figura del Dr. Juan Bartolomé, jefe del primer Servicio de Emergencia de la entonces AECID, creada a partir de una unión de institutos de cooperación técnica (IGMA, ICI...) integrados bajo una agencia de reciente creación. Por la insistencia del Dr. Bartolomé se crea una unidad que depende directamente del gabinete de AECI y, por tanto, del entonces máximo responsable: su secretario general.

El departamento, con un presupuesto muy escaso que rondaba el millón de euros, se centraba en el seguimiento de un pequeño programa de asistencia alimentaria, única y exclusivamente para Cabo Verde, con un marcado carácter político, y en generar una mínima capacidad de despliegue capaz de dar asistencia médica en catástrofes.

La crisis de los Grandes Lagos provoca por primera vez un importante despliegue sanitario en Ruanda que reafirma a los responsables políticos de la época la necesidad de generar capacidades más amplias de respuesta a emergencias.

A principios del siglo XXI se producen los primeros intentos de profesionalización. Siguiendo el convencimiento político de que la acción humanitaria ha de ser parte de la acción de la cooperación española y, por tanto, de su acción exterior, se crea la primera unidad dedicada a la ayuda humanitaria con un ánimo más amplio. En primer lugar, se comienza a invertir realmente en las capacidades propias de respuesta españolas con la generación de un equipo, la apertura de los centros logísticos humanitarios de Torrejón y Panamá y la ampliación de fondos, pese a que continúan siendo escasos y no existe una auténtica doctrina en la AECID que asuma los principios de neutralidad, independencia e imparcialidad que impone la actividad y que ha aceptado la comunidad internacional con los Principios de Buena Donación Humanitaria.

La AECID procura, con su escaso presupuesto, abrir un camino en la cooperación a agencias humanitarias de la familia de las Naciones Unidas. Llevando a cabo las primeras aportaciones a agencias como el Programa Mundial de Alimentos (PMA), el alto comisionado de las Naciones Unidas para los Refugiados (ACNUR), el Fondo de las Naciones Unidas para la Infancia (UNICEF), etc. Estas aportaciones, sin ser significativas, tienen que superar los problemas administrativos de una normativa que no está adaptada a este tipo de actores que además en muchas ocasiones resultan nuevos.

\section{La acción}

humanitaria

española tiene una corta historia de aprendizaje en la que pasa de ser una herramienta de asistencia de emergencia a constituirse poco a poco en una auténtica y consolidada acción humanitaria 
Al final de esta etapa, España ha culminado un proceso de integración como donante en las grandes agencias humanitarias y ha superado con buenos resultados su primer gran despliegue de esta fase durante el tsunami de Indonesia. Si bien todavía no se ha creado una cultura sobre lo que es la acción humanitaria, se ha conseguido despertar un fuerte interés político y lo humanitario forma parte de la agenda política, no solo por su capacidad recién probada, sino también por el enorme apoyo social que genera.

Tras la reforma de la AECI para convertirse en la AECID bajo el régimen de agencias estatales, llega el gran boom de la acción humanitaria en España. Con la "refundación" de la agencia se crea exnovo la Oficina de Acción Humanitaria $(\mathrm{OAH})$ como una dirección general dentro de la agencia. Al mismo tiempo se dota la acción humanitaria con un presupuesto aproximado de 340 millones de euros y España entra como un gran actor en la donación humanitaria.

Pese al gran incremento presupuestario y la generación de un nuevo equipo específicamente dedicado a la acción humanitaria, España continúa sin asimilar los Principios de la Buena Donación Humanitaria y se confunde a menudo lo que es humanitario de lo que no. Durante el primer periodo de la OAH se producen grandes desembolsos que, sin embargo, no obedecen a una política clara, ni siquiera por un sesgo político definido. Más bien se distribuyen algunos fondos sin criterio definido y otros por instrucciones políticas que no obedecen a criterios claros.

Tras una entrada algo errática, la OAH define por primera vez, a finales de la primera década del siglo XXI, una estrategia humanitaria que obedece a principios preestablecidos, de carácter estrictamente humanitario y que se hacen públicos. Los técnicos de la OAH desarrollan una serie de criterios que de forma simple pueden resumirse de la siguiente manera:

a) El presupuesto humanitario español corresponde aproximadamente a un $1 \%$ del Global Consolidated Appeal, por lo que España procurará contribuir en un $1 \%$ a los llamamientos de Naciones Unidas en cada una de las crisis humanitarias que sean de larga duración (protracted) o emergencias (sudden crisis).

b) Identificado el llamamiento e identificando aquellos sectores con menor nivel de financiación, España trabajará con las agencias líderes de dicho sector en la identificación de necesidades. Se considerarán al mismo tiempo las aéreas de mayor experiencia de la cooperación española o aquellas en las que España tenga más capacidad de incidencia o aportación técnica.

c) España procurará mantener el mismo reparto porcentual de aportación a las distintas agencias con el fin de hacer sus contribuciones lo más predecibles posibles.

Al mismo tiempo, y con el fin de asegurar la predictibilidad no solo financiera, sino también en cuanto a las prioridades, la nueva OAH lidera los nuevos marcos de asociación con las agencias con el fin de trabajar con ellas en el alineamiento de sus prioridades con las prioridades de la cooperación española.

Durante esta fase y en lo relativo a su acción directa en emergencias, España enfrenta una de las respuestas más grandes en términos de despliegue de su corta historia: el terremoto de Haití, que combina un despliegue de varios relevos de más de 100 técnicos entre personal logístico, médico y de rescate con la aportación a organismos multilaterales y ONG.
España ha culminado un proceso de integración como donante en las grandes agencias humanitarias y ha superado con buenos resultados su primer gran despliegue de esta fase durante el tsunami de Indonesia 
Gráfico 2. Evolución del presupuesto de la Acción Humanitaria española en millones de euros (2004-2013)

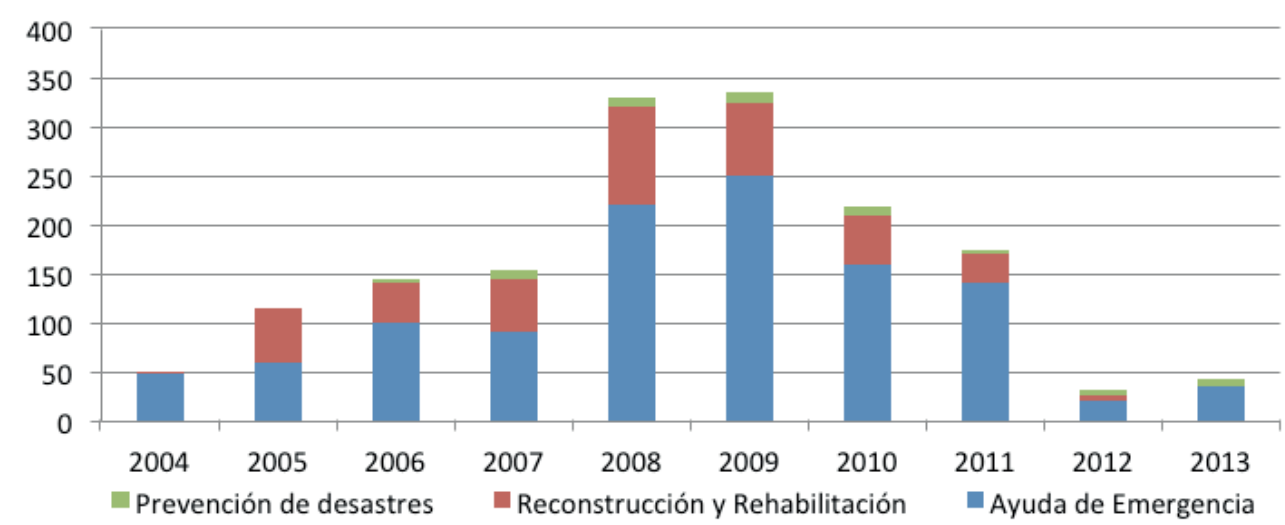

Fuente: Informe sobre la Realidad de la Ayuda con datos a partir del Plan Anual de Cooperación Internacional (PACI). Gráfico elaboración propia

Con la llegada de la crisis económica y tras la gran restricción de fondos producida por la misma, la OAH se suma a las directrices generales de la AECID de priorizar la acción humanitaria en aquellos sectores donde existan unos mayores intereses de carácter histórico, económico, político, etc. Esta fase, ampliamente criticada por su contradicción con los Principios de la Buena Donación Humanitaria, viene acompañada por una dramática reducción de fondos que pasan de unos 240 millones de euros a 22 millones de euros y posteriormente 16 millones de euros.

La OAH, en la que se imponían los principios de vulnerabilidad sobre los criterios políticos propios de la ayuda al desarrollo, se ve forzada a trabajar en aquellos países determinados como prioritarios en el Plan Director de la Cooperación. Esta premisa se ve, sin embargo, inmediatamente forzada por la necesidad de España de acudir a escenarios originalmente no prioritarios por la presión internacional de nuestros países aliados. Este es el caso de Siria, que no es parte del plan director originalmente, pero al que la AECID se ve obligada a aportar por ser una prioridad de carácter político y estratégico. Lo mismo puede decirse de la crisis generada por el estallido del Ébola en África del Oeste.

En definitiva, si bien es cierto que la acción humanitaria tiene un corto recorrido, sí es verdad que ha conseguido abrirse un camino dentro del engranaje institucional español y presentarse como una parte de lo que se ha dado en llamar la "marca España". Los instrumentos para una auténtica acción humanitaria se han creado y, poco a poco, se ha ido generando una conciencia de lo que supone la ayuda humanitaria respecto a la ayuda al desarrollo. Durante los últimos años, y debido a las restricciones presupuestarias, se han transferido a la misma principios más propios del desarrollo como la concentración geográfica. Pese a todo se ha ido generando, gracias al trabajo de la propia OAH y la incidencia de las principales ONG humanitarias, una cultura de lo que es humanitario y de lo que no lo es. El camino para dejar clara esa diferencia tanto a la ciudadanía como a sus representantes políticos es todavía largo. Pero parte de una clara distinción dentro del propio sector y del uso no oportunista de la etiqueta humanitaria por parte de todos los actores. 


\section{Conclusiones}

El sistema de cooperación internacional española se ha consolidado como una de las herramientas más eficaces de la acción exterior del Estado hasta el 2010. Como parte de una política pública, obedece a la necesidad de actuar en base, por un lado, a unos criterios asumidos por España en las diferentes organizaciones internacionales de las que nuestro país forma parte y, por otro lado, a la solidaridad de nuestro país en relación con la reducción de la pobreza. No obstante, la política de cooperación internacional para el desarrollo es, ante todo, eso: política exterior de España.

Como consecuencia, España ha consolidado un complejo sistema de actores e instrumentos en torno al funcionamiento de la política de cooperación internacional. Los actores del sistema de cooperación española son diversos y plurales. La política de cooperación está dirigida desde el Gobierno de la nación, a través del Ministerio de Asuntos Exteriores y de Cooperación, pero participan en el proceso global actores públicos (ministerios, comunidades autónomas, ayuntamientos y universidades), pasando por organizaciones no gubernamentales e incluso organizaciones y empresas privadas. En relación con los instrumentos, España canaliza los fondos públicos a través de todos estos actores y, de forma significativa, a través de organismos internacionales multilaterales.

La política de cooperación internacional para el desarrollo ha sido una de las más damnificadas de la crisis económica y financiera internacional, víctima casi mortal de los recortes presupuestarios llevados a cabo en los últimos años. Pero esta decisión de reducir los fondos de cooperación internacional casi hasta su desaparición también tiene una fuerte carga ideológica. De esta forma, la cooperación al desarrollo española ha pasado de ser una de las más potentes dentro del contexto internacional a convertirse en una de las menos representativas de la comunidad donantes miembros de la OCDE.

En relación con la acción humanitaria se ha producido un crecimiento y popularización en los últimos años que no ha ido acompañado de un aumento del conocimiento sobre esta y, mucho menos, de un mayor respeto a los principios y valores que dan sentido al humanitarismo. La situación actual ha obligado a redimensionar una acción humanitaria que debe seguir guiándose por los principios de humanidad, imparcialidad, neutralidad e independencia.

Si bien es cierto que la acción humanitaria tiene un corto recorrido en el caso español, sí es verdad que ha conseguido abrirse un camino dentro del engranaje institucional español. Los instrumentos para una auténtica acción humanitaria se han creado y, poco a poco, se ha ido generando una conciencia de lo que supone la ayuda humanitaria respecto a la ayuda al desarrollo. Si durante los últimos años, y debido a las restricciones presupuestarias, se han transferido a la misma principios más propios de la cooperación al desarrollo como la concentración o priorización geográfica, pese a todo se ha ido generando gracias al trabajo de la propia Oficina de Acción Humanitaria y la incidencia de las principales ONG humanitarias una cultura de lo que es humanitario y de lo que no lo es. El camino para dejar clara esa diferencia, tanto a la ciudadanía, como a sus representantes políticos es todavía largo. Pero parte de una clara distinción dentro del propio sector y del uso no oportunista de la etiqueta humanitaria por parte de todos los actores.

\section{Bibliografía}

Boni Aristizábal, A., Calabuig Tormo, C., Cuesta Fernández, I., Gómez-Torres, M. de los Ll., Lozano Aguilar, J. F., Monzó Balbuena, J. M., \& Torres Martínez, J. A. (2010). La cooperación internacional para el desarrollo. En C. Calabuig \& Llanos M. de los Ll. Gómez- 
Torres (Coords. serie), Cuadernos de Cooperación para el Desarrollo: N. ${ }^{\circ} 1$. Valencia: Universidad Politécnica de Valencia.

Calvillo Cisneros, J. M., \& Yuste Echarren, P. (2015). El Sistema de Cooperación Internacional español. En Manual de Atención Integral en Catástrofes y Cooperación Internacional. Madrid: Universidad Camilo José Cela.

Estrategia de la Acción Humanitaria Española. [Consultada el 15 de diciembre de 2017] http:// www.dicc.hegoa.ehu.es/listar/mostrar/1

Intermon Oxfam. (2015). Informe sobre la realidad de la Ayuda de Intermon Oxfam. [Consultada el 15 de diciembre de 2015]. http://www.oxfamintermon.org/es/informate/publicaciones/estudios

Ley 23/1998 de la Cooperación Internacional para el Desarrollo. [Consultada el 10 de diciembre de 2017]. http://www.cooperacionespanola.es/sites/default/files/legislacion_espanola_en_cooperacion-compilacion_informativa_0.pdf

Oficina de Acción Humanitaria de España. [Consultada el 25 de noviembre de 2017] http://www.aecid.es/Centro-Documentacion/Documentos/Planificaci\%C3\%B3n\%20 estrat\%C3\%A9gica\%20por\%20sectores/DES_AH.pdf

Olivié, I., \& Pérez, A. (2014). Cooperación financiera reembolsable: ¿qué hacen otros donantes y qué puede hacer España? Real Instituto Elcano, 31/03/2014. [Consultado el 12/12/2017]. http://www.realinstitutoelcano.org/wps/portal/web/rielcano_es/contenido?WCM_ GLOBAL_CONTEXT=/elcano/elcano_es/zonas_es/cooperacion+y+desarrollo/policypaper-olivie-perez-cooperacion-financiera-reembolsable-espana-donantes

Plan Director de la Cooperación Española 2013-2016. [Consultado el 10 de diciembre de 2017] http://www.cooperacionespanola.es/sites/default/files/plan_director_cooperacion_espanola_2013-2016.pdf 